Revue d'histoire de l'Amérique française

6. REVUE D.HISTOIRE DE L'AMÉRIQUE FRANÇAISE

\title{
Lettre inédite concernant un Acadien
}

Volume 24, numéro 1, juin 1970

URI : https://id.erudit.org/iderudit/302957ar

DOI : https://doi.org/10.7202/302957ar

Aller au sommaire du numéro

Éditeur(s)

Institut d'histoire de l'Amérique française

ISSN

0035-2357 (imprimé)

1492-1383 (numérique)

Découvrir la revue

Citer ce document

(1970). Lettre inédite concernant un Acadien. Revue d'histoire de l'Amérique française, 24(1), 85-87. https://doi.org/10.7202/302957ar d'utilisation que vous pouvez consulter en ligne.

https://apropos.erudit.org/fr/usagers/politique-dutilisation/ 


\section{DOCUMENTS INÉDITS}

\section{LETTRE INÉDITE CONCERNANT UN ACADIEN}

Note: Cette lettre d'un Acadien adressée à $M$. le Président de la Convention a été copiée par M. Pierre Massé. Elle est extraite des Archives Nationales, cote D III 296. Nous ajoutons au document une bibliographie des travaux de M. Pierre Massé relatifs aux Acadiens en Poitou qui nous est parvenue grâce aux soins de MM. Pierre Menanteau et Jean-Guy Pilon.

Monsieur,

de Montmorillon, 9 nov. 1792.

Permettez qu'un infortuné frappe vos oreilles de ses plaintes. Je suis Canadien. J'ai été pris deux fois par les Anglais, en 1756, en Acadie, et en 1758 à l'Isle royale ou Cap Breton, en 1759 à Québec et en 1760 à la Martinique. Nous avons perdu les tristes restes d'une fortune assez brillante. J'ai essuyé, dès l'âge le plus tendre, tant sur mer que sur terre, les plus grands malheurs. Mes malheureux parents, ayant tout perdu, vinrent se jeter dans les bras de la mère patrie. J'ai été fait prêtre et fus assez heureux, après des pertes immenses, d'être promu à la cure de Lathus, qui, pour toute richesse, me donnait la congrue de 700 livres et près de 2000 pauvres.

Le décret du 27 novembre 1790 me priva de tout. Je refusai le serment sous la réserve de mes croyances. J'aurais cru être méprisable aux yeux de l'Assemblée constituante si j'en avais agi autrement:

Car renoncer aux dieux que l'on croit dans son cœur,

Est le crime d'un lâche et non pas une erreur.

C'est trahir à la fois, sous un masque hypocrite,

Et le Dieu qu'on préfère et le Dieu que l'on quitte.

C'est mentir au ciel même, à l'univers, à soi. ${ }^{1}$

J'ai été aussitôt relevé et privé de la pension de 500 livres quoi que mon explication fût du 31 mars, et le décret qui m'en privait du mois de juin suivant.

${ }^{1}$ De qui sont ces vers? 
Le glaive étincelant toujours sur ma tête innocente, je n'ai cependant cessé d'être soumis à la loi et d'en être le plus zélé observateur. Cette même tête qui a failli périr mille fois par le fer ennemi et par la tempête, s'est vue exposée à de plus grands dangers, puisque ceux même à qui j'avais sauvé la vie ont attenté à la mienne. Succombant enfin à la rigueur du sort, un mal aigu s'est déclaré et m'a mis hors d'état d'obéir au décret qui a ordonné notre exportation. ${ }^{2}$ La maladie qui empire ne me met que la mort devant les yeux. A mon âge, dans mon malheur, où porter mes regards appesantis, où pourrais-je lever des yeux obscurcis d'un nuage de pleurs ? A qui avoir recours dans l'excès de mes maux ? A vous, monsieur, à l'équité de la Convention nationale. J'ai trop de confiance en elle pour craindre un refus. Elle est juste, mais est pleine de bontés. A elle seule appartient de sécher les larmes d'un mal malheureux qui, j'ose le dire, ne méritait pas de l'être. Non, elle est trop équitable et trop compatissante pour refuser un morceau de pain, mais, si elle le fait, du moins, ah ! du moins, qu'elle me permette de me transporter de dessus le lit de douleur où la charité publique arrête les tristes restes d'une vie qui s'enfuit, dans mon domicile, qui est à deux lieues d'ici, où je ne serais plus à charge dans mon indigence, ce qui augmente encore à mes peines.

Je suis innocent. Si je ne l'eusse été, j'eusse éprouvé la rigueur des lois. J'ai l'honneur d'être connu de monsieur Bornière, député du département de Poitiers, du district et de la municipalité de Montmorillon sous la sauvegarde et la surveillance de laquelle je suis. Je défie que l'on ait rien à me reprocher, dans le plus grand besoin, accablé sous le poids de la maladie, vivant d'aumônes. Quoique cette pensée m'accable, je pourrais cependant finir chez moi des jours empoisonnés par les plus cruels et amers chagrins.

Daignez faire entendre, je vous en supplie, ma triste et faible voix dans le sein de notre compatissante Assemblée qui, si elle le veut bien, ne tardera pas à me procurer au plus tôt la grâce urgente que je sollicite de son humanité.

J'ai l'honneur d'être avec le plus profond respect, Monsieur, votre très humble et très soumis serviteur.

[François] Roy, prêtre, ci-devant curé de Lathus ${ }^{3}$

2 traduire déportation. Les prêtres ayant refusé le serment furent expulsés. Beaucoup se rendirent en Espagne, d'autres en Suisse.

3 Département de la Vienne. 
Bibliographie de travaux relatifs aux Acadiens en Poitou

Pierre Massé, "Le syndic de la colonie acadienne en Poitou", Revue d'histoire de l'Amérique française, V (no 1): 45-68, (no 2): 252-264, (no 3) : 373-400;

- "Descendances acadiennes - Les quatre filles de Marie-Reine Berbudeau", ibid, V (no 4): 531-541; VI (no 2): 252-262; VII (no 3): 426-434;

- "Destinées acadiennes - La courte vie de Marie Doucet", Mémoires de la Société généalogique canadienne-française (Montréal 1953): 166-170;

"Les rapports sociaux entre Acadiens et Poitevins", L'Actualité de l'Histoire (Paris, 1955);

- "Problèmes acadiens en Poitou", Bulletin de la Société des Antiquaires de l'Ouest (Poitiers, 1952) : 293-311; 1963): 49-71;

- “Destinées acadiennes en Poitou", ibid. (Poitiers, 1966) : 627-645. 